\title{
UMA ANÁLISE DO DECRETO NACIONAL DE ALFABETIZAÇÃO: REFLEXÕES ACERCA DO MÉTODO FÔNICO
}

\author{
AN ANALYSIS OF THE NATIONAL LITERACY DECREE: \\ REFLECTIONS ABOUT THE PHONIC METHOD
}

\author{
Jace Mari Costa | Lattes \\ Universidade Federal de Santa Catarina - PROFLETRAS \\ Yara de Oliveira Marcomini | Lattes | yara.om@bol.com.br \\ Universidade Federal de Santa Catarina - PROFLETRAS
}

\begin{abstract}
Resumo: O presente artigo objetiva apresentar uma contextualização da história dos métodos de alfabetização no Brasil e uma reflexão do método fônico implementado por decreto no Plano Nacional de Alfabetização. O intuito é mostrar, a partir dos estudos de Mortatti (2006), que a discussão acerca de um método salvacionista existe desde quando a escola foi universalizada, no final do século XIX. Desde então se defende a implementação de um método em detrimento de outro. A Política Nacional de Alfabetização aposta no método fônico para erradicar o analfabetismo no Brasil e este artigo apresenta reflexões acerca deste método, que defende a consciência fonológica como pré-requisito para que o sujeito seja alfabetizado, com o propósito de mostrar que a escolha do método deve estar atrelada a necessidade do indivíduo e que a apropriação da leitura e da escrita supera o processo de instrumentalização.
\end{abstract}

Palavras-chave: História dos Métodos. Alfabetização. Consciência fonológica. Decreto 9.765. Método fônico.

\begin{abstract}
This article aims to present a contextualization of the history of literacy methods in Brazil and a reflection on the phonic method implemented by decree in the National Literacy Plan. The aim is to show, from Mortatti's (2006) studies, that the discussion about a salvationist method has existed since the school was universalized in the late nineteenth century and the implementation of one method over another has been advocated. The National Literacy Policy bets on the phonic method to eradicate illiteracy in Brazil and this article, which reflects on this method that defends phonological awareness as a prerequisite for the subject to be literate, and on the purpose of showing that the choice of the literacy method must be linked to the individual need and to the appropriation of reading and writing surpassing the instrumentalization process.
\end{abstract}

Keywords: History of Methods. Literacy. Phonological awareness. Decree 9,765. Phonic method. 


\section{INTRODUÇÃO}

Procura-se, analisar neste artigo, o decreto no 9.765, de 11 de abril de 2019, que institui a Política Nacional de Alfabetização, com o objetivo de explicitar que a forma como se orienta o trabalho educativo se sobrepõe à escolha metodológica no processo de alfabetização. O presente artigo está organizado em duas seções de conteúdo, seguidas das considerações finais.

Na primeira delas, faremos uma contextualização dos estudos de Mortatti (2006), da história dos métodos de alfabetização no Brasil e da ideia de resolução do problema da alfabetização atrelado à escolha metodológica.

$\mathrm{Na}$ segunda seção, apresentaremos o decreto da Nova Política Nacional de Alfabetização que mantém o foco no método fônico, bem como as polêmicas geradas em torno do documento e, para contextualização, faremos uma abordagem sobre o método fônico e consciência fonológica.

\section{HISTÓRIA DOS MÉTODOS DE ALFABETIZAÇÃO NO BRASIL}

Tratando-se da história da alfabetização, Araújo (1996) destaca que alguns períodos aparecem bem marcados,

[...] o primeiro inclui a Antiguidade e a Idade Média, quando predominou o método da soletração; o segundo teve início pela reação contra o método da soletração, entre os séculos XVI e XVIII, e se estendeu até a década de 1960, caracterizando-se pela criação de novos métodos sintéticos e analíticos; e o terceiro período, marcado pelo questionamento e refutação da necessidade de se associar os sinais gráficos da escrita aos sons da fala para aprender a ler, iniciou em meados da década de 1980 com a divulgação da teoria da Psicogênese da língua escrita" (ARAÚJO, 1996, p. 112).

Com o intuito de contextualizar a história dos métodos de alfabetização no Brasil e a ideia da resolução do problema da alfabetização associado à escolha metodológica, apresentaremos um apanhado geral dos estudos de Mortatti (2006) acerca desse tema. Esse estudo é uma síntese de alguns resultados de pesquisas desenvolvidas, há mais de duas décadas, a respeito do ensino da leitura e escrita na fase inicial de escolarização de crianças, que foi denominado como alfabetização a partir do século XX.

De acordo com Mortatti (2006, p. 2), a dificuldade das crianças em aprender a ler e a escrever sempre gerou uma grande discussão acerca dos métodos de alfabetização utilizados, especialmente no final do século XIX. Desde então, para atender aos ideais 
republicanos, a escola consolidou-se como um lugar necessariamente institucionalizado para preparar as novas gerações, que propunha o "esclarecimento das massas iletradas".

A partir de 1930, ler e escrever se tornou o principal índice de medida e testagem da eficiência da escola pública. Surgiram, então, problemas, ora de método, ora de ensino, trazendo o fracasso escolar e o insucesso na leitura e na escrita, foi instigando gestores públicos e intelectuais de diferentes áreas de conhecimento, educadores e professores.

[...] as últimas três décadas assistiram a mudanças de paradigmas teóricos no campo da alfabetização que podem ser assim resumidas: um paradigma behaviorista, dominante nos anos de 1960 e 1970, e substituído, nos anos de 1980, por um paradigma cognitivista, que avança, nos anos de 1990, para um paradigma sociocultural. (SOARES, 2003, p. 9)

A escola foi universalizada, tornando-se acessível a toda a população, a chamada democratização escolar. A leitura e a escrita, que até então eram restritas a poucos - e aconteciam de maneira mais informal e de forma rudimentar no âmbito dos lares, ou de maneira menos informal nas poucas "escolas" do império -, tornou-se obrigação das escolas. Vistas como tecnicamente ensináveis, as práticas de leitura e escrita foram organizadas sistematicamente e para isso surgiu a necessidade de profissionais especializados para a aplicação das técnicas.

Inicialmente, a alfabetização na fase de escolarização da criança era vista como uma passagem para um mundo novo, o mundo público da cultura letrada, no qual o sujeito alcançaria novos modos e conteúdos de pensar, sentir, querer e agir. Porém, especialmente nas duas últimas décadas, a associação entre escola e alfabetização vem sendo questionada, pois os efeitos pretendidos com a ação da escola sobre o cidadão não vêm sendo concretizados. O problema ora é associado ao método de ensino, ora ao aluno, ao professor, ao sistema escolar, às condições sociais ou às políticas públicas. O fato é que esse problema não é exclusivo da atualidade. Um estudo introdutório do estado da arte da pesquisa sobre o fracasso escolar no Brasil (ANGELUCCI et al., 2004) revela vertentes que o compreendem, de acordo com o momento histórico, como problema essencialmente psíquico; como problema meramente técnico; como questão institucional; como questão profundamente política.

Desde a implementação do modelo republicano de escola, pode-se observar os esforços realizados para solucionar o que hoje é denominado "fracasso escolar na alfabetização". Por quase um século, os esforços se concentraram em torno de uma mudança dos métodos utilizados para o ensino da leitura e da escrita. As disputas entre o método tradicional contra o método revolucionário dividiu os estudiosos e educadores. 
O fracasso do processo de alfabetização/letramento, em muitos momentos, aparece associado a práticas pedagógicas e métodos de ensino. Para Soares (2004a):

A discussão sobre método de alfabetização é hoje, difícil, porque se apresenta sempre contaminada por duas questões. Em primeiro lugar, o fato de que o problema de aprendizagem da leitura e da escrita tenha sido considerado, no quadro de paradigmas conceituais tradicionais, como um problema, sobretudo metodológico, tem levado a que se rejeitem métodos de alfabetização ao mesmo tempo em que se rejeitem esses paradigmas que já não mais são aceitos. Em segundo lugar, e em estreita relação com a questão anterior, "método", na área da alfabetização, tornou-se um conceito estereotipado[...] (SOARES, 2004a, p. 93).

Podemos encontrar, de acordo com Mortatti (2006), quatro movimentos na história da alfabetização no Brasil. O primeiro se dá por volta de 1876, com a publicação, em Portugal, da Cartilha Maternal ou Arte da Leitura, escrita pelo poeta português João de Deus.

Antes dele, o método utilizado era o da marcha sintética, o ensino iniciava-se partindo da apresentação das letras e dos sons correspondentes, indo para a silabação, sempre com ordem crescente de dificuldade. Posteriormente ensinava-se a ler as palavras e depois ensinavam-se frases isoladas ou agrupadas. $\mathrm{O}$ ensino da escrita restringia-se a caligrafia e ortografia, e seu ensino, à cópia, ditados e formação de frases. $\mathrm{O}$ ensino da leitura iniciava-se com as chamadas "cartas de $\mathrm{ABC}$ ” e depois se liam e se copiavam documentos manuscritos.

A partir do início da década de 1880, marca-se o primeiro momento com o "método João de Deus" ou "método da palavração", trazido ao Brasil pelo positivista militante e professor de português da Escola Normal de São Paulo Antonio da Silva Jardim, que consistia em iniciar o ensino da leitura pela palavra, para depois analisá-la a partir dos valores fonéticos das letras.

Esse primeiro momento se estende até o início da década de 1890 e nele tem início uma disputa entre os defensores do "método João de Deus" e aqueles que continuavam a defender e utilizar os métodos sintéticos. Com essa disputa enfatiza-se o como ensinar metodicamente, relacionado com o que ensinar.

O segundo momento é marcado a partir de 1890, quando implementou-se a reforma da instrução pública no estado de São Paulo. Com a pretensão de servir de modelo para os demais estados, a base da reforma estava nos novos métodos de ensino, em especial no então revolucionário método analítico para o ensino da leitura. De acordo com o 
método analítico, o ensino da leitura deveria ser iniciado pelo "todo": a palavra, ou a sentença, ou a "historieta”. Esse método foi defendido e amplamente disseminado por meio de "missões de professores” paulistas, instrução pública, instruções normativas, cartilhas e artigos em jornais e em revistas pedagógicas.

O método tornou-se obrigatório nas escolas públicas paulistas, embora a maioria dos professores reclamassem da lentidão de resultados desse método. Buscando se adequar às instruções oficiais, as cartilhas passaram a contemplar o método de marcha analítica. Iniciou-se, então, uma disputa entre os defensores do método sintético com os defensores do método analítico.

Em meados da década de 1920, aumentaram as resistências dos professores quanto à utilização do método analítico. Por outro lado, os defensores do método analítico continuaram a utilizá-lo e a propagar sua eficácia, mas buscando conciliar os dois tipos básicos de métodos de ensino da leitura e escrita, nomeados por métodos mistos ou ecléticos, considerados mais rápidos e eficientes. Marca-se aí o início do terceiro momento.

$\mathrm{O}$ tom de combate e defesa de um ou outro método foi diluindo-se gradativamente, na medida em que se relativizou a importância do método, que decorreu da institucionalização das então novas e revolucionárias bases psicológicas da alfabetização contidas no livro Testes $A B C$ para verificação da maturidade necessária ao aprendizado da leitura e escrita. A proposta do estudo era medir o nível de maturidade necessária ao aprendizado, a fim de classificar os alfabetizandos, visando à organização de classes homogêneas e à racionalização e eficácia da alfabetização.

O estudo de Angelucci et al. (2004) revela que a característica do momento inaugural da pesquisa educacional, que teve início no interior dos órgãos governamentais, foi “a presença forte da leitura psicológica do processo de educação escolar, e consequentemente, de estudos da psicologia do ensino e da aprendizagem e a criação de instrumentos de avaliação psicológica e pedagógica do aprendiz. No auge da influência da Escola Nova, a pedagogia científica era assentada na biologia e na psicologia.

Desse viés, a importância do método de alfabetização passou a ser relativizado, secundarizado e considerado tradicional. No entanto, observa-se ainda a permanência da função instrumental do ensino e aprendizagem da leitura, simultaneamente com o ensino da escrita, que ainda eram entendidas como habilidades visuais, auditivas e motoras.

Nesse terceiro momento, que vai até o final da década de 1970, funda-se uma outra tradição no ensino da leitura e da escrita: a alfabetização sob medida, resultando no ensino subordinado à maturidade da criança, ou seja, as questões de ordem didática subordinadas às de ordem psicológica. 
O quarto momento é marcado a partir do início da década de 1980, quando surgiram novas urgências políticas e sociais que fizeram acompanhar propostas de mudança na educação para enfrentar o fracasso da escola na alfabetização de crianças. Dessa forma o ensino tradicional passou a ser questionado. Introduziu-se no Brasil o pensamento construtivista sobre alfabetização, resultante das pesquisas sobre a psicogênese da língua escrita desenvolvida pela pesquisadora argentina Emília Ferreiro e colaboradores. $\mathrm{O}$ construtivismo não se apresenta como método, mas como "revolução conceitual” e questiona a necessidade das cartilhas.

Emília Ferreiro não propõe um novo método de ensino da escrita, compreendendo que a aprendizagem não depende de métodos: “[...] o método (enquanto ação específica do meio) pode ajudar ou frear, facilitar ou dificultar, porém não criar a aprendizagem. A obtenção do conhecimento é um resultado da própria atividade do sujeito" (FERREIRO, TEBEROSKY, 1991[1985], p. 28-29 apud CHRAIM, EMERICK, 2016, p. 119).

É importante ressaltar que, mesmo com as considerações das autoras em não configurar um método de alfabetização, os estudos foram difundidos no Brasil como tal.

Verifica-se desta forma um grande esforço, por parte de autoridades educacionais e de pesquisadores acadêmicos, de convencimento dos alfabetizadores para a apropriação do construtivismo. Inicia-se, então, uma disputa entre os defensores do construtivismo e os defensores do método tradicional.

Ao longo do período histórico observa-se a disputa pela hegemonia de determinados métodos de alfabetização. A proposta do novo método sempre acontecia em detrimento do anterior, que era esvaziado de qualidade e identificado como decadente. De acordo com Frade (2007, p. 35 apud CHRAIM; EMERICK, 2016, p. 121),

[...] um problema que se constata na história dos métodos é que estes sempre vieram atrelados a um discurso único de eficiência, sem consideração dos limites internos de cada um, mas apenas dos problemas dos métodos que os precederam. Alguns autores vão dizer que a discussão dos métodos, historicamente, é fruto muito mais de um discurso apaixonado do que de evidências racionais sobre seus progressos.

De acordo com Saviani (2012), uma pedagogia articulada com os interesses populares se empenha para que a escola funcione bem, e portanto está interessada em métodos eficazes. Esses métodos superarão os métodos tradicionais e novos quando incorporarem as contribuições de ambos.

A escola precisa considerar os interesses dos alunos, os ritmos de aprendizagem e o desenvolvimento psicológico, mas sem perder de vista a sistematização lógica dos conhe- 
cimentos, bem como seu processo de transmissão-assimilação dos conteúdos cognitivos, sem deixar de valorizar o diálogo com a cultura acumulada historicamente. Os métodos preconizados por Saviani vinculam educação e sociedade e devem ser avaliados não em si mesmo, mas nas consequências que produziram historicamente.

Em 2019, um dos primeiros atos do governo brasileiro de Jair Bolsonaro foi a criação da Secretaria de Alfabetização - Sealf, chefiada pelo youtuber Carlos Nadalim, defensor da educação em casa e livreiro on-line. Nadalim introduziu uma nova Política Nacional de Alfabetização (BRASIL, 2019b) que prioriza a "fonética”, abordagens para o ensino da leitura e da escrita que se concentram nas palavras sonoras, associando assim os fonemas com seus grafemas correspondentes, às vezes contrastando com abordagens de palavra inteira focadas no significado. Nadalim não é apenas um defensor vocal da fonética, mas um oponente veemente de todas as outras abordagens à alfabetização, explicitamente aquelas associadas a Paulo Freire (1921-1997) e, implicitamente, as que emergem de Nova York (BATISTA; WINDLE, 2019).

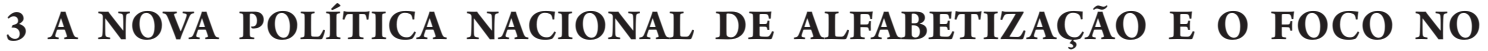 MÉTODO FÔNICO}

O Brasil tem uma política que regulamenta o processo de alfabetização e, no dia 11 de abril de 2019, foi publicado no Diário Oficial da União o Decreto no 9.765 que institui a Política Nacional de Alfabetização que pretende erradicar o analfabetismo no Brasil apostando no método fônico (ou fonético) de alfabetização e tem por público-alvo: crianças na primeira infância; alunos dos anos iniciais do ensino fundamental; alunos da educação básica regular que apresentam níveis insatisfatórios de alfabetização; alunos da educação de jovens e adultos; jovens e adultos sem matrícula no ensino formal e alunos das modalidades especializadas de educação.

Art. $1^{\circ}$ Fica instituída a Política Nacional de Alfabetização, por meio da qual a União, em colaboração com os Estados, o Distrito Federal e os Municípios, implementará programas e ações voltados à promoção da alfabetização baseada em evidências científicas, com a finalidade de melhorar a qualidade da alfabetização no território nacional e de combater o analfabetismo absoluto e o analfabetismo funcional, no âmbito das diferentes etapas e modalidades da educação básica e da educação não formal. (BRASIL, 2019b).

Nas Disposições Gerais do Capítulo I do Decreto 9.765, em seu Art. 2º é trazida a explicação dos termos utilizados no decreto e o que representam: 
Alfabetização - ensino das habilidades de leitura e de escrita em um sistema alfabético, a fim de que o alfabetizando se torne capaz de ler e escrever palavras e textos com autonomia e compreensão;

Analfabetismo absoluto - condição daquele que não sabe ler nem escrever;

Analfabetismo funcional - condição daquele que possui habilidades limitadas de leitura e de compreensão de texto;

Consciência fonêmica - conhecimento consciente das menores unidades fonológicas da fala e a habilidade de manipulá-las intencionalmente;

Instrução fônica sistêmica - ensino explícito e organizado das relações entre os grafemas da linguagem escrita e os fonemas da linguagem falada; Fluência em leitura oral - capacidade de ler com precisão, velocidade e prosódia;

Literacia - conjunto de conhecimentos, habilidades e atitudes relacionadas com a leitura e a escrita e sua prática produtiva;

Literacia familiar - conjunto de práticas e experiências relacionadas com a linguagem, a leitura e a escrita, as quais a criança vivencia com seus pais ou cuidadores;

Literacia emergente - conjunto de conhecimentos, habilidades e atitudes relacionadas com a leitura e a escrita, desenvolvidos antes da alfabetização;

Numeracia - conjunto de conhecimentos, habilidades e atitudes relacionadas com a matemática; Educação não formal - designação dos processos de ensino e aprendizagem que ocorrem fora dos sistemas regulares de ensino. (BRASIL, 2019b).

Os termos "literacia" e "numeracia", que são utilizados no Decreto, dão uma aparência de novo, mas segundo Mortatti (2019), em entrevista à revista Nova Escola, não é uma diferença semântica, mas política e provavelmente escolheram usar "literacia" para não usar "letramento". A justificativa na PNA para adoção do termo Literacia é para "alinhar-se à terminologia científica consolidada internacionalmente" (BRASIL, 2019b, p. 21), porém Batista (2019) apud Favretto (2018) diz que a substituição do termo ocorre porque Nadalim, identifica o conceito letramento como fruto ideológico do "marxismo cultural".

Ainda sobre os conceitos de alfabetização e de literacia, a PNA ressalta que não se tem no país uma compreensão objetiva do processo de alfabetização.

A palavra alfabetização é muitas vezes usada de modo impreciso, resultando confusão pedagógica e didática, dificuldade de diálogo entre as pessoas envolvidas na educação, além de desconhecimento para os pais, que muitas vezes acreditam que seus filhos foram alfabetizados, quando, na verdade, mal sabem ler palavras. (BRASIL, 2019b, p. 18). 
No entanto, Monteiro (2019) diz que o paradigma educacional de alfabetização adotado no país, e reconhecido internacionalmente há pelo menos duas décadas, tem tratado a aprendizagem da língua escrita a partir da compreensão de dois processos distintos, mas indissociáveis: a alfabetização e o letramento. A pesquisadora cita as produções da especialista Magda Soares que já apresenta a distinção entre os termos alfabetização e letramento há mais de vinte anos:

Ao desconsiderar as áreas das ciências linguísticas e pedagógicas, a PNA restringe as possibilidades da ação educativa nas escolas quando desvincula o ensino explicitamente voltado para o desenvolvimento de habilidades de consciência fonêmica e da decodificação de palavras (BRASIL, 2019, p. 28) de outras dimensões da aprendizagem da língua escrita, que também devem estar presentes na prática pedagógica de forma explícita e sistemática. (MONTEIRO, 2019, p. 3).

O Decreto prevê que os programas e as ações do Plano Nacional de Alfabetização devem ter ênfase no ensino de seis componentes essenciais para alfabetização: consciência fonêmica; instrução fônica sistemática; fluência em leitura oral; desenvolvimento de vocabulário; compreensão de textos e produção de escrita.

A pressão pela fonética no Brasil "repete" movimentos e discursos políticos mobilizados em vários cenários nacionais nos últimos 30 anos, começando nos EUA na década de 1990, quando houve um "envolvimento político direto nos métodos de ensino da alfabetização" apoiado por "um coalizão conservadora de legisladores, fundações, cristãos fundamentalistas e seus acadêmicos aliados. (BATISTA; WINDLE, 2019).

A opinião de especialistas da área da educação, mais precisamente da alfabetização indica que a Política Nacional da Educação não apresenta toda a discussão a respeito das relações entre leitura e escrita no processo inicial de aquisição e não são consideradas ou problematizadas as mudanças que ocorreram, a partir das interrelações entre o ato de escrever e $o$ ato de ler, em cada tempo e na sociedade contemporânea (FRADE, 2019).

Conforme consta no Documento, A Política Nacional de Alfabetização (BRASIL, 2019b) será implementada por meio de programas, ações e instrumentos que incluem, entre outros, orientações curriculares e metas claras e objetivas para a educação infantil e para os anos iniciais do ensino fundamental e desenvolvimento de materiais didático-pedagógicos cientificamente fundamentados para a literacia emergente, a alfabetização e a numeracia, e de ações de capacitação de professores para o uso desses materiais na educação infantil e nos anos iniciais do ensino fundamental. 
Compete ao Ministério da Educação a coordenação estratégica dos programas e ações decorrentes da Proposta Nacional de Alfabetização que terá a colaboração por adesão voluntária dos entes federativos. Para fins de implementação, a União poderá prestar assistência técnica e financeira aos entes federativos.

Ainda que a adesão entre os estados e municípios seja voluntária, impor um método pedagógico específico e condicionar sua adoção à assistência federal é um assunto polêmico já que o método escolhido não é um consenso entre especialistas em alfabetização. Especialistas e professores procuram propor a conciliação entre diferentes abordagens com foco na aprendizagem dos alunos, já a proposta do governo impõe um único método e, contrariando essa perspectiva conciliatória, apresenta uma única opção em substituição às pluralidades conceituais e metodológicas já abordadas na alfabetização.

O processo de alfabetização não se configura apenas como ensino, mas também como aprendizagem. Essa omissão representa retrocesso na compreensão da alfabetização enquanto processo que envolve relação entre sujeitos que interagem com objetos de conhecimento (LOPES, 2019).

Não há um debate amplo favorável ao método fônico, pois ele separa o sujeito do seu contexto de aprendizagem, desconsidera a subjetividade do aluno, eliminando-o do protagonismo no processo de aprender. $\mathrm{O}$ contexto social é ignorado e os sujeitos são concebidos como se oriundos de uma mesma realidade. É importante que no processo educativo o aluno seja considerado como criador do conhecimento e não apenas como consumidor, dessa forma permite-se que a criança pense sobre a linguagem e se torne um sujeito reflexivo que cria, elabora e reelabora suas produções textuais (BATISTA, WINDLE. 2019).

\subsection{CONSCIÊNCIA FONOLÓGICA}

Consciência fonológica é a capacidade que a pessoa desenvolve para compreender e refletir sobre a estrutura sonora da língua. Ao adquirir essa consciência, a pessoa percebe que as palavras são segmentáveis em sílabas e fonemas.

Consciência Fonológica é uma habilidade, entre outras, fundamental para o desenvolvimento da leitura e escrita. É importante notar que o radical "fono", de origem grega, significa "sons". Sendo assim., a consciência fonológica refere-se à capacidade mental de refletir sobre a estrutura sonora da fala. O método fônico, por sua vez, é uma abordagem, uma opção no processo de alfabetização. Portanto, independentemente do método utilizado é sempre possível, se não necessário, o treino da consciência fonológica. (CAPOVILLA; CAPOVILLA, 2003, p. 13). 
A capacidade de se dar atenção ao significado do enunciado implica a aptidão de se centrar nos sons da fala. Enquanto a consciência fonológica se refere à habilidade de reconhecer as componentes fonológicas das unidades linguísticas e segmentar mentalmente de forma consciente, os comportamentos epifonológicos são comportamentos apresentados desde cedo pelas crianças. Esses comportamentos inadvertidos e inconscientes revelam a discriminação prematura dos sons. Segundo Soares (2018):

Pode-se considerar surpreendente, em se tratando da aprendizagem de um sistema de escrita que representa os sons da fala, que somente a partir do início dos anos 1970 tenha sido reconhecida a importância de que a criança, para compreender o princípio alfabético, desenvolva sensibilidade para a cadeia sonora da fala e reconhecimento das possibilidades de sua segmentação - desenvolva consciência fonológica. (SOARES, 2018, p. 167, grifos da autora).

A relação entre as letras e os sons da fala é complexa, porque a escrita não é como um espelho da fala, existem várias maneiras de se ler o que está escrito. Os sinais gráficos existentes na escrita do português conferem um valor sonoro especial às letras e sinais modificadores da entonação da fala, são os chamados sinais diacríticos: acento agudo, acento circunflexo, acento grave, ponto de interrogação, ponto de exclamação, til, aspas, ponto final, reticências etc. "O nosso sistema de escrita, o Português, usa vários tipos de alfabeto e, mesmo assim não é totalmente alfabético, pois além das letras ele se compõe também com outros caracteres ideográficos, como os sinais de pontuação e os números.” (CAGLIARI, 2006,p.107).

\subsubsection{Consciência de Palavras}

Consciência de palavras ou consciência sintática representa a capacidade de segmentar a frase em palavras, perceber a relação entre elas e organizá-las numa sequência que dê sentido:

[...] a escrita, individualizando as palavras pela separação delas por espaços em branco, faz com que a criança passe a identificá-las na fala tomando como referência a representação gráfica [... ] (SOARES, 2018, p. 173).

Essa habilidade tem influência mais precisa na produção de textos e não no processo inicial de aquisição de escrita. Ela permite focalizar as palavras e sua posição na frase. Além disso, ordenar corretamente uma oração ouvida com as palavras desordenadas também é uma capacidade que depende desta habilidade. 


\subsubsection{Consciência silábica}

Consciência silábica consiste na capacidade de segmentar as palavras em sílabas. Essa habilidade depende da capacidade de realizar análise e síntese vocabular.

São atividades como contar o número de sílabas, dizer qual é a sílaba inicial, medial ou final de uma determinada palavra e também contar, segmentar, unir, adicionar, suprimir, substituir e transpor uma sílaba da palavra formando um novo vocábulo.

O passo inicial da fonetização da escrita é a escrita silábica: capaz de recortar oralmente a palavra em sílabas, e já compreendendo que a escrita representa os sons das palavras, e que estes são representados por letras, a criança começa a escrever silabicamente - a usar as letras para representar os recortes orais que identifica nas palavras: neste momento inicial, as sílabas. (SOARES, 2018, p. 187).

Os níveis de consciência lexical e consciência de rimas e aliterações precedem o período de fonetização da escrita, mas são fundamentais para a aprendizagem de um sistema alfabético de escrita. Segundo Soares (2018), esses níveis de consciência "levam a criança a focalizar o som das palavras, dissociando-o de seus significados”. Embora fundamentais, esses níveis não são suficientes porque a criança ainda não alcançou o princípio alfabético através da segmentação da palavra e o relacionamento de segmentos orais com representações gráficas, até o nível do fonema.

\subsubsection{Consciência fonêmica}

A consciência fonêmica (fonemas, segmentos, sons da fala) é desenvolvida quando a criança entra para o $10^{\circ}$ ciclo da alfabetização. A capacidade fonêmica permite à criança a aprendizagem da escrita com maior facilidade. Essa capacidade fonêmica é a mais refinada da consciência fonológica, e é também a última a ser adquirida pela criança.

\footnotetext{
É a natureza abstrata dos fonemas e a impossibilidade de reconhecê-los e pronunciá-los isoladamente que explica porque pesquisas constatam, reiteradamente, a dificuldade de reconhecimento e manipulação consciente de fonemas, ao contrário do que ocorre com as tarefas de reconhecimento e manipulação de rimas e de sílabas, que se revelam em geral fáceis. (SOARES, 2018, p. 199).
}

Atividades como dizer quais ou quantos fonemas formam uma palavra; descobrir qual palavra está sendo dita por outra pessoa unindo os fonemas por ela emitidos; formar novas palavras subtraindo o fonema inicial da palavra (por exemplo, excluindo o fonema 
[k] da palavra CASA, forma-se a palavra ASA), são exemplos em que se utiliza a consciência fonêmica.

Os segmentos sonoros não possuem significados em si mesmos, mas permitem diferenciar uma unidade linguística significativa (semantema) de outra.

Exemplo 1:

PALAVRA FONEMA

FACA $\backslash \mathbf{f} \backslash \backslash \mathbf{a} \backslash \backslash \mathbf{k} \backslash \backslash \mathbf{a} \backslash$

VACA $\backslash \mathbf{v} \backslash \backslash \mathbf{a} \backslash \backslash \mathbf{k} \backslash \backslash \mathbf{a} \backslash$

No caderno que descreve a Política Nacional de Alfabetização (BRASIL,2019b), o Ministério afirma que a consciência fonológica é "essencial" no processo de aprendizagem e escrita. $\mathrm{O}$ documento descreve esse termo como uma habilidade de identificação e manipulação da linguagem oral.

\subsection{MÉTODO FÔNICO}

A escrita é um complexo sistema de representação simbólica e o método fônico é uma representação dos sons da fala por meio de símbolos/letras. De acordo com autores que convergem com o método fônico, este permite que o aluno tenha uma compreensão do som das letras, sílabas e palavras, levando a uma escrita com uma melhor consciência fonológica. A metodologia é muito utilizada na aprendizagem de alunos com dificuldades de leitura, sendo muito praticada na alfabetização de pessoas com dislexia. Países como França, Inglaterra e Estados Unidos adotaram essa metodologia para corrigir sua pedagogia de alfabetização.

A maioria das escolas brasileiras não privilegia o ensino da relação entre o som (fonema) e a letra (grafema). As crianças aprendem o nome das letras e na tentativa da escrita acabam realizando espontaneamente a correspondência entre o nome das letras e os sons.

No método fônico, a alfabetização se dá através da associação entre um símbolo (a letra, ou grafema) e seu som (o fonema). A criança aprende a reconhecer o som de cada letra para, a partir daí, ser capaz de combiná-las de modo a formar sílabas e palavras. O ensino se inicia pela forma e pelo som das vogais, seguidas pelas consoantes. Parte-se dos sons mais simples para os mais complexos. 


\begin{abstract}
Através de vários estudos notou-se que é imprescindível o ensino das relações entres os sons e as letras no processo de alfabetização. As crianças aprendem mais rápido por este caminho, pois desenvolvem plenamente o hemisfério cerebral esquerdo, especializado na linguagem. Por outro lado, nos métodos globais (nos quais a criança aprende inicialmente o sentido da palavra, sem a decodificação letra-som), o lado direito é ativado. (LIVOX, 2018).
\end{abstract}

Durante o processo de alfabetização, deve-se criar oportunidades para que o aluno tenha consciência do som das palavras, frases, sílabas e fonemas como unidades separadas e saiba reconhecê-las. Devem-se desenvolver atividades que auxiliam nesse desenvolvimento como exercícios que envolvam rimas, segmentação fonêmica e discriminação de sons, que ensinem as relações entre as letras e os sons. Segundo Capovilla e Capovilla (2003, p. 7), "ao desenvolver tais habilidades os alunos começam a pronunciar com bastante precisão nos momentos de leitura em voz alta, ditado e compreensão de textos.”

A aplicação do método fônico possui uma sequência didática para a realização das atividades. O livro "Alfabetização: Método Fônico" de Fernando Capovilla e Alessandra Sebra (2010) traz essa sequência com um rol de atividades que se inicia com o reconhecimento das vogais A, E, I, O e U, sendo trabalhadas depois as consoantes.

Há registros formais do uso do método fônico desde 1719, na França. No Brasil, ele passou a ser amplamente usado em substituição ao método alfabético, que vigorou até a década de 1980. Atualmente, o método fônico rivaliza com as técnicas associadas ao construtivismo, em que se parte de textos e experiências sobre as funções da linguagem rumo a palavras, letras e sons, considerado mais moderno. "O texto é resultado de ação e, portanto, a centralidade do texto significa que a alfabetização é sempre vista como questão de ação social e forças sociais, e todos os aspectos da alfabetização são vistos como decorrentes dessas ações e forças.” (BATISTA, 2019 apud KRESS, 2007, p. 86).

Se pensarmos no fim do trabalho de alfabetização como instrumentalização apenas, ou seja, codificação e decodificação, o método fônico é suficiente e tem como característica uma resposta mais rápida. Porém se pensarmos na alfabetização comprometida com a humanização, ela envolve o processo de instrumentalização, mas esse não é o principal objetivo. O movimento de humanização contempla o movimento de compreensão crítica, de autonomia, de reconhecimento do sujeito histórico com possibilidade de transformação social.

Nesse sentido, as práticas de leitura como atividades humanas significam a necessidade e relevância para a vida dos envolvidos. Ensinar a ler como atividade humana e não 
apenas como aquisição de habilidades individuais envolve intencionalidade (GOMES, 2019). Nesse caso, a consciência fonológica não é uma condição e sim uma consequência previsível do processo.

\subsection{AS POLÊMICAS ACERCADA POLÍTICA NACIONAL DE ALFABETIZAÇÃO PRESENTES NO PLANO NACIONAL DE EDUCAÇÃO}

A Base Nacional Comum Curricular BNCC (BRASIL, 2019a), estabelece que a alfabetização deve ser realizada nos dois primeiros anos do Ensino Fundamental, com o terceiro ano como prazo limite, destacando em suas orientações aos professores a perspectiva construtivista, visto que a consciência fonológica como treino é compreendida nessa perspectiva. Já o Decreto n 9.765, de 11 de abril de 2019, que institui a Política Nacional de Alfabetização, traz alguns pontos polêmicos, como a priorização do método fônico e a referência à primeira infância como um dos públicos alvos do programa. Também não foi especificado no documento como o Plano Nacional de Educação - PNE (BRASIL, 2014c) irá dialogar com a BNCC (BRASIL, 2019a), que já estabelece competências e direitos de aprendizagem específicos para alunos da Educação Infantil e do Ensino Fundamental.

A diretriz vem causando polêmica entre educadores, que consideram o método ultrapassado e ineficaz para a aprendizagem das crianças. A defesa é que o método fônico faça parte do processo de alfabetização, mas não seja o único método. Entre os especialistas é defendida a dimensão do letramento, que prevê - além da associação de grafemas e fonemas - o uso social da leitura e escrita. (BASILIO, 2019).

De acordo com a publicação de Basilio (2019), na reportagem para o Especial Educação em Disputa, o novo secretário de Alfabetização do Ministério da Educação (MEC), Carlos Nadalim, nas redes sociais, condenou o letramento como vilão da alfabetização, classificando-o como uma reinvenção construtivista da alfabetização. Em entrevista à Carta Educação, a professora emérita da Universidade Federal de Minas Gerais - (UFMG) e pesquisadora do Centro de Alfabetização, Leitura e Escrita (Ceale), Magda Soares rebate as críticas do secretário e afirma que defender o método fônico como alternativa para a agenda é uma atitude simplista e ignorante. Na entrevista, Magda Soares esclarece que o letramento não é vilão, mas sim parceiro da alfabetização:

O construtivismo não é um método de ensino, é uma teoria de aprendizagem da área da psicologia cognitiva que se aplica não só à língua, 
mas a qualquer outro conteúdo. [...] O que o construtivismo trouxe para nós é que a criança aprende progressivamente conceitos culturais e isso acontece em todas as áreas, até para amarrar o sapato há essa construção. E aprender a ler e a escrever é mais ou menos isso, a professora orienta a criança a como construir. Resumindo, são coisas diferentes, letramento, alfabetização e construtivismo. Naladim faz uma verdadeira salada disso, que mostra a sua falta de clareza entre teorias, aprendizagem do princípio alfabético e uso social da língua escrita. (SOARES, 2019).

Já o presidente do Instituto Alfa e Beto, João Batista Oliveira, em entrevista à revista Nova Escola, declarou que acha positivo que o decreto tenha dado luz à adoção do método fônico na alfabetização: "Há avanços conceituais importantes, que por si só merecem comemoração. No meio de tantas ameaças, sabotagem e atos de guerrilha, a equipe responsável pelo decreto deve ser parabenizada pelo feito. Comecemos pelos avanços.” (OLIVEIRA, 2019).

O texto do PNA (2019b) não explicita claramente um modelo específico de Alfabetização a ser adotado, mas os termos "consciência fonêmica" e "instrução fônica sistemática" são mencionados na lista de componentes essenciais aos quais será dada ênfase no ensino.

Para a criança aprender a língua escrita, é preciso que ela aprenda as relações entre os fonemas e as letras. Ela tem que aprender como ocorre a representação da língua oral na escrita. Para Soares (2019), o processo de alfabetização inclui a aprendizagem pela criança das relações fonemas e grafemas, mas não é só isso. “Tem muita coisa que antecede esse momento em que a criança se sente capaz de entender essas relações”.

O primeiro grupo do público alvo, no documento, são as crianças na primeira infância e no grupo dos agentes envolvidos aparecem os professores de Educação Infantil. O termo "primeira infância" refere-se a crianças de 0 a 5 anos, permitindo então, que se pense metas de aprendizagem de alfabetização para crianças desta faixa etária.

A "literacia emergente" ou a introdução das crianças da Educação Infantil no universo letrado, por si só, tem grande apoio de professores e especialistas. $\mathrm{O}$ embate começa quando se discute como isso deve ser feito. Enquanto construtivistas acreditam que a abordagem deve ser através da contação de histórias, da exploração dos livros pelas crianças, do contato com diferentes tipos de textos em situações cotidianas e da escrita de garatujas (aqueles rabiscos que, aos olhos dos adultos, não fazem sentido, mas para as crianças é uma forma de expressarem o que querem escrever), o professor João Batista de Oliveira, por exemplo, acredita que é necessário, de fato, introduzir formalmente o processo de Alfabetização às crianças desde muito cedo. (PERES, 2019). 
Sobre a Educação familiar, o Decreto (BRASIL, 2019a) se refere à Educação feita pela família e, segundo Mortatti (2019), na entrevista à Nova Escola, da forma como está sendo imposto, irá permitir que se fortaleça a Educação não formal.

Conforme apontado pela Ação Educativa (2019) no Indicador de Analfabetismo Funcional - INAF, há uma parcela da população que, embora alfabetizada, não se letrou. Esses dados apontam que, em 2018, 3 em cada 10 brasileiros eram analfabetos funcionais e, para Soares (2019), isso deve piorar se insistirmos na ideia de que o letramento é o vilão da alfabetização, como pode-se observar nos Quadro1 e Tabela 1:

Quadro 1 - Níveis de Alfabetismo

\begin{tabular}{|c|c|c|}
\hline & Niveis de Alfabetism & \\
\hline $\begin{array}{c}\text { Utilizados até } 2011 \\
\text { (4 niveis) }\end{array}$ & GRUPOS & $\begin{array}{c}\text { Utilizados a partir de } 2015 \\
\text { (5 niveis) }\end{array}$ \\
\hline Analfabeto & \multirow{2}{*}{$\begin{array}{l}\text { ANALFABETOS } \\
\text { FUNCIONAIS }\end{array}$} & Analfabeto \\
\hline Rudimentar & & Rudimentar \\
\hline Básico & \multirow{3}{*}{$\begin{array}{l}\text { FUNCIONALMENTE } \\
\text { ALFABETIZADOS }\end{array}$} & Elementar \\
\hline \multirow[b]{2}{*}{ Pleno } & & Intermediário \\
\hline & & Proficiente \\
\hline
\end{tabular}

Fonte: AÇÃO EDUCATIVA, 2019.

Tabela 1 - Níveis de Alfabetismo no Brasil (2001-2018)

\begin{tabular}{|c|c|c|c|c|c|c|c|c|c|}
\hline Nivel & $\begin{array}{l}2001 \\
2002\end{array}$ & $\begin{array}{l}2002 \\
2003\end{array}$ & $\begin{array}{l}2003 \\
2004\end{array}$ & $\begin{array}{l}2004 \\
2005\end{array}$ & 2007 & 2009 & 2011 & 2015 & 2018 \\
\hline BASE & 2000 & 2000 & 2001 & 2002 & 2002 & 2002 & 2002 & 2002 & 2002 \\
\hline Analfabeto & $12 \%$ & $13 \%$ & $12 \%$ & $11 \%$ & $9 \%$ & $7 \%$ & $6 \%$ & $4 \%$ & $8 \%$ \\
\hline Rudimentar & $27 \%$ & $26 \%$ & $26 \%$ & $26 \%$ & $25 \%$ & $20 \%$ & $21 \%$ & $23 \%$ & $22 \%$ \\
\hline Elementar & $28 \%$ & $29 \%$ & $30 \%$ & $31 \%$ & $32 \%$ & $35 \%$ & $37 \%$ & $42 \%$ & $34 \%$ \\
\hline Intermediário & $20 \%$ & $21 \%$ & $21 \%$ & $21 \%$ & $21 \%$ & $27 \%$ & $25 \%$ & $23 \%$ & $25 \%$ \\
\hline Proficiente & $12 \%$ & $12 \%$ & $12 \%$ & $12 \%$ & $13 \%$ & $11 \%$ & $11 \%$ & $8 \%$ & $12 \%$ \\
\hline Total $^{2}$ & $100 \%$ & $100 \%$ & $100 \%$ & $100 \%$ & $100 \%$ & $100 \%$ & $100 \%$ & $100 \%$ & $100 \%$ \\
\hline $\begin{array}{l}\text { Analfabeto } \\
\text { Funcional* }\end{array}$ & $39 \%$ & $39 \%$ & $37 \%$ & $37 \%$ & $34 \%$ & $27 \%$ & $27 \%$ & $27 \%$ & $29 \%$ \\
\hline $\begin{array}{l}\text { Funcionalmente } \\
\text { Alfabetizados* }\end{array}$ & $61 \%$ & $61 \%$ & $63 \%$ & $63 \%$ & $66 \%$ & $73 \%$ & $73 \%$ & $73 \%$ & $71 \%$ \\
\hline
\end{tabular}

Fonte: AÇÃO EDUCATIVA, 2019. 
Ao analisar os níveis de alfabetismo no país, o Inaf coloca em debate o próprio significado de analfabetismo, que não pode se restringir a uma visão binária de alfabetizado x não-alfabetizado e sim de um processo gradativo de aquisição e consolidação de habilidades.

A Política Nacional da Alfabetização (PNA) lançada em 15 de agosto de 2019, juntamente com um Caderno de Apresentação, logo após a publicação no Diário Oficial da União do Decreto no 9.765 que institui a Política Nacional de Alfabetização, traz em sua apresentação a justificativa de que a realidade educacional "revela urgência na mudança da concepção de políticas voltadas à alfabetização, à literacia e à numeracia. Para sustentar essa justificativa, o documento apresenta dados da Avaliação Nacional da Alfabetização - ANA, (BRASIL, 2016) e do Indicador de Analfabetismo Funcional - INAF (AÇÃO EDUCATIVA, 2019)

Especialistas explicam que o uso desses percentuais para justificar o insucesso da alfabetização obscurece a construção de diagnósticos mais precisos sobre as reais necessidades de intervenções pedagógicas. As avaliações da ANA foram acompanhadas por questionários contextuais e isso vai além dos dados produzidos por testes cognitivos, mas isso é omitido no documento (MICARELLO, 2019).

A PNA ignora ou omite os dados do Índice de Desenvolvimento do Ensino Básico - IDEB (BRASIL, 2007) que apontam para mudanças significativas, devido às ações de políticas educacionais anteriores. Tanto as políticas educacionais quanto as produções anteriores são negadas e desqualificadas no documento quando cita que a PNA é baseada em evidências científicas.

Martins (2019) ressalta que os programas governamentais anteriores também se pautaram em evidências e fundamentos científicos. Lopes (2019) diz que dessa forma a nova política descontinua as políticas públicas e a partir do seu texto, desconstrói e invalida os feitos anteriores.

A PNA está fundamentada teoricamente nas ciências cognitivas, adotando apenas uma área de conhecimento, parte de um único referencial teórico. Ao estabelecer uma única linha de atuação, o documento legitima "práticas que desconhecem o que é aprendizagem significativa, esvaziadas de conteúdo e desconectadas das práticas sociais e culturais nas quais tem sentido e valor ler e escrever." (CARDOSO et al., 2019, s/p.). Reduzir o alfabetizando a uma única faceta o inviabiliza enquanto sujeito histórico. 


\section{CONSIDERAÇÕES FINAIS}

A pesquisa contextualiza a história dos métodos de alfabetização no Brasil, na perspectiva histórico-cultural, trazendo concepções de sujeito e de língua bastante marcadas na relação com o social e com a interação. É preciso que a escola considere os interesses dos alunos, os ritmos de aprendizagem e o desenvolvimento psicológico, mas sempre considerando a sistematização lógica dos conhecimentos e seu processo de transmissão e assimilação.

Os autores demonstram que a perspectiva do letramento aponta para um sujeito capaz de exercer a condição de alfabetizado, sendo interlocutor do texto, compreendendo, aceitando ou questionando aquilo que se lê. $\mathrm{O}$ processo de tradução de um texto escrito em letras e sílabas não significa que o sujeito compreende o que está escrito.

Pelo viés histórico-cultural, a figura do professor é apresentada como a de quem exerce um papel determinante no que se refere aos processos de ensino e aprendizagem, sendo ele o outro mais experiente do qual a criança, em processo de alfabetização, depende. Nessa perspectiva, os docentes são os responsáveis por um planejamento que contemple as necessidades dos seus alunos, incidindo diretamente no desenvolvimento desses. Os professores são chamados a assumir uma responsabilidade-chave para a efetivação dos processos de ensino e aprendizagem.

Quando o papel do professor é secundarizado e em contrapartida se estimula o uso de materiais padronizados, não enxerga-se a individualidade dos alunos enquanto sujeitos oriundos das diversas esferas sociais. É necessário compreender que as crianças são seres sociais e como tal, chegam à escola com conhecimentos sobre a escrita, dos quais se apropriaram antes de sua entrada na esfera escolar.

A pesquisa apresenta o decreto da Nova Política Nacional de Alfabetização, demonstrando que o plano nacional de educação retroage em relação a toda essa discussão e elege o método fônico como o único método para realizar o processo de alfabetização e aponta apenas para a ideia da codificação e decodificação.

As crianças têm o direito de ingressar numa cultura letrada e para tanto é preciso que os responsáveis pela alfabetização conheçam o que já foi apresentado como modo de pensar, sentir, querer e agir dos alfabetizadores. De posse desse conhecimento, compreendemos que não podemos apostar em métodos salvacionistas, mas simplistas.

Estabelecer uma política pública para tratar da alfabetização requer longos debates entre pesquisadores, especialistas e professores que defendem diferentes métodos, regras e tempos de aprendizagem. Deve-se levar em consideração seus argumentos, pesquisas e evidências científicas. 
Apesar da importância da consciência fonológica, é necessário o desenvolvimento das demais habilidades envolvidas no processo de alfabetização. A metodologia de associar letras a seus sons ainda é adotada no Brasil e em outros países, mas críticos a consideram ultrapassada e defendem a mistura de métodos. Enquanto que no método fônico a consciência fonológica é uma condição, no processo de letramento ela se torna uma consequência.

A questão dos métodos é apenas um aspecto de uma teoria educacional relacionada com a teoria do conhecimento. A instrumentalização é necessária sim para que o sujeito desenvolva um processo de consciência, criticidade e de autonomia, porém a codificação e decodificação não devem ser o ponto de chegada no processo de letramento que apontam para resultados mais objetivos e mensuráveis. De acordo com Saviani (2012), é a prática social que deve ser o ponto de partida e o ponto de chegada no processo de letramento.

\section{REFERÊNCIAS}

ANGELUCCI, C. B.; KALMUS, J.; PAPARELLI, R.; PATTO, M. H. O estado da arte da pesquisa sobre o fracasso escolar (1991-2002): um estudo introdutório. Educação e Pesquisa, São Paulo, v. 30, n. 1, p. 51-72, jan./abr. 2004.

ARAÚJO, Mairce. Ambiente Alfabetizador: a sala de aula como entre - lugar de culturas. In: GARCIA, Regina. Novos Olhares sobre a Alfabetização. São Paulo: Brasiliense, 1996.

BASILIO, Ana Luiza. Pensar que se resolve alfabetização com método fônico éignorância. Ação Educativa. 18 Abr. 2019. Disponível em: https://www.cartacapital.com.br/educacao/ pensar-que-se-resolve-a-alfabetizacao-com-o-metodo-fonico-e-uma-ignorancia/. Acesso: 21 Ago. 2019.

BATISTA, S.; WINDLE, J. A circulação global de políticas de alfabetização: o método fônico, desigualdade e movimentos políticos neoconservadores. Revista Brasileira de Linguística Aplicada, V. 19, n. 2, p. 385-406, 2019. Disponível em: http://dx.doi. org/10.1590/1984-6398201915478. Acesso: 20 jun. 2020.

BRASIL. Ministério da Educação. Base Nacional Comum Curricular. Brasília, 2019a.

BRASIL. Ministério da Educação. Avaliação nacional da alfabetização (ANA): documento básico. Brasília: INEP, 2016. Disponível em: . Acesso em: 20 jun. 2020.

BRASIL. Índice de Desenvolvimento da Educação Básica (Ideb). Brasília: Instituto Nacional de Estudos e Pesquisas Educacionais Anísio Teixeira, Série Documental, Textos para Discussão, 2007.

BRASIL. Decreto n. 9.765, de 11 de abril de 2019. Institui a Política Nacional de Alfabetização. Diário Oficial da União: seção 1 - Extra, Brasília, DF, Edição 70-A, p. 15, 11 abr. 2019b. 
BRASIL. Lei Federal 13.005, de 25 de junho de 2014. Aprova o Plano Nacional de Educação - PNE e dá outras providências. Brasília, DF, 25.

CAGLIARI, Luiz Carlos. Alfabetização \& linguística. Editora Scipione, 2006.

CARDOSO, B.; GUIDA, A.; SEPÚLVEDA, A.; PAULET, N. Contribuição para o debate sobre alfabetização a propósito do lançamento da PNA. Revista Brasileira de Alfabetização, n. 10. Edição Especial, 2019. Disponível em: http://revistaabalf.com.br/index.html/ index.php/rabalf/article/view/372. Acesso em 19 jun. 2020.

CAPOVILLA, A. G. S.; CAPOVILLA, F. C. Alfabetização: Método fônico. São Paulo, SP: 2003. Memnon Crítica 13 (1), 7-24.

CAPOVILLA, Fernando; SEABRA, Alessandra G. Alfabetização: Método Fônico. 5. ed. São Paulo: Memmon, 2010.

CHRAIM, A. M.; MARIA de, M. S. E. O Ensino e a Aprendizagem da Língua Escrita num Viés Histórico: Os Métodos de Alfabetização, os Estágios Implicacionais e a Perspectiva Histórico-Cultural. In: SILVEIRA, Everaldo... [et al.]. Alfabetização na Perspectiva do Letramento: Letras e Números nas Práticas Sociais. Florianópolis: UFSC/CED/NUP, 2016.

GOMES, Maria F. C. A PNA e a unidade dialética afeto-cognição nos atos de ler e escrever. Revista Brasileira de Alfabetização, n. 10. Edição Especial, 2019. Disponível em: http:// revistaabalf.com.br/index.html/index.php/rabalf/article/view/368. Acesso em 19 jun. 2020.

FAVRETTO, A. Carlos Nadalim, o crítico de Paulo Freire que está conquistando as famílias na internet. Sempre Família, [Sl], 2018. Disponível em: Disponível em: https://www. semprefamilia.com.br/carlos-nadalim-o-critico-de-paulo-freire-que-esta-conquistandoas-familias -na-internet. Acesso em: 20 jun. 2020.

FRADE, Isabel C. A. S. A escrita na Política Nacional da Alfabetização. Revista Brasileira de Alfabetização, n. 10. Edição Especial, 2019. Disponível em: http://abalf.org.br/wpcontent/uploads/2019/10/A-escrita-na-PNA-Isabel-Frade.pdf. Acesso em 19 jun. 2020.

INAF 2018. Indicador de Alfabetismo Funcional. Ação Educativa. 2019. Disponível em https://ipm.org.br/inaf Acesso: 16 Ago. 2019.

LIVOX. A importância do método fônico no processo de alfabetização. Disponível em: https://livox.institutobrasildeeducacao.com.br/pt/artigos-livox/a-importancia-dometodo-fonico-no-processo-de-alfabetizacao/. Acesso 25 de Ago. 2019.

KRESS, G. Literacy in the New Media Age. Londres; Nova York: Routledge, 2007.

LOPES, Denise M. C. Considerações sobre a Política Nacional de Alfabetização. Revista Brasileira de Alfabetização, n. 10. Edição Especial, 2019. Disponível em: http:/ / revistaabalf. com.br/index.html/index.php/rabalf/article/view/359. Acesso em 19 jun. 2020.

MARTINS, Maria. S. C. Vale ou não a pena? Revista Brasileira de Alfabetização, n. 10. Edição Especial, 2019. Disponível em: http://revistaabalf.com.br/index.html/index. php/rabalf/article/view/365. Acesso em 19 jun. 2020. 
MICARELLO, Hilda. Alfabetização e evidências. Revista Brasileira de Alfabetização, n. 10. Edição Especial, 2019. Disponível em: http://abalf.org.br/wp-content/ uploads/2019/10/ALFABETIZA\%C3\%87\%C3\%83O-E-EVID\%C3\%8ANCIASHilda-Micarello.pdf. Acesso em 21 jun. 2020.

MONTEIRO, Sara M. A concepção de alfabetização na Política Nacional de Alfabetização. Revista Brasileira de Alfabetização, n. 10. Edição Especial, 2019. Disponível em: http:// revistaabalf.com.br/index.html/index.php/rabalf/article/view/351. Acesso em 19 jun. 2020.

MORTATTI, Maria Rosário Longo. História dos Métodos de Alfabetização no Brasil. Conferência proferida durante o Seminário "Alfabetização e letramento em debate", realizado em Brasília, em 27/04/2006. Disponível em: https://fbnovas.edu.br/site/ wp-content/uploads/2019/02/Acervo\%20em\%20PDF/Hist\%C3\%B3rias\%20dos\%20 M\%C3\%A9todos\%20de\%20Alfabetiza\%C3\%A7\%C3\%A3o\%20no\%20Brasil.pdf. Acesso em 19 jun. 2020.

MORTATTI, Maria Rosário Longo. A "Política Nacional de Alfabetização" (Brasil, 2019): uma "guinada" (ideo) metodológica para trás e pela direita. Revista Brasileira de Alfabetização, n. 10. Edição Especial, 2019. Disponível em: http://revistaabalf.com.br/ index.html/index.php/rabalf/article/view/348. Acesso em 19 jun. 2020.

OLIVEIRA, João Batista. O decreto da alfabetização. Veja. 12 Abr. 2019. Disponível em: https://veja.abril.com.br/blog/educacao-em-evidencia/o-decreto-da-alfabetizacao/.

PERES, Paula. Política Nacional de Alfabetização: entenda as polêmicas presentes na PNA. Nova Escola. Disponível em: https://novaescola.org.br/conteudo/17139/entenda-aspolemicas-presentes-na-politica-nacional-de-alfabetizacao. Acesso: 03 mai. 2019.

SAVIANI, Dermeval. Escola e Democracia. 42. ed. Campinas, SP: Autores Associados, 2012 [1983]. - (Coleção polêmicas do nosso tempo; 5)

SAVIANI, Dermeval. Letramento e alfabetização: as muitas facetas. Rev. Bras. Educ. [online].2004,n.25,pp.5-17.ISSN 1809-449X. Dispónível em: https://doi.org/10.1590/ S1413-24782004000100002. Acesso: 18 jun 2020.

SOARES, Magda. Letramento e escolarização. In: RIBEIRO, Vera Masagão (Org.). Letramento no Brasil. São Paulo: Global, 2004a. p. 89-113.

SOARES, Magda. Alfabetização: a questão dos métodos. São Paulo: Contexto, 2018.



Data de submissão: 08/01/2020

Data de aceite: $20 / 04 / 2020$ 


\section{ANEXO A - Decreto no 9.765 de 11 de Abril de 2019}

DECRETO No 9.765, DE 11 DE ABRIL DE 2019 - Diário Oficial da União - Imprensa Naciona

\section{DIÁRIO OFICIAL DA UNIÃO}

Publicado em: 11/04/2019 | Edição: 70-A | Seção; 1 - Extra | Página: 15

Orgäo: Atos do Poder Executivo

\section{DECRETO N 9.765, DE 11 DE ABRIL DE 2019}

Institui a Politica Nacional de Alfabetização.

O PRESIDENTE DA REPÚBLICA, no uso da atribuição que the confere o art. 84 , caput, inciso IV, da Constituição, $\Theta$ tendo em vista o disposto no art. $8^{\circ}, \S 1^{\circ}$, da Lei $n^{\circ} 9.394$, de 20 de dezembro de 1996 , e no art. $2^{\circ}$, caput ,inciso 1 , da Lei $n^{\circ} 13.005$, de 25 de junho de 2014 ,

DECRETA :

CAPITULO I

DISPOSIÇÕES GERAIS

Art. $1^{\circ}$ Fica instituida a Politica Nacional de Alfabetização, por meio da qual a União, em colaboração com os Estados, Distrito Federal e os Municípios, implementará programas e açōes voltados à promoção da alfabetização baseada em evidências cientificas, com a finalidade de melhorar a qualidade da alfabetização no território nacional e de combater o analfabetismo absoluto e o analfabetismo funcional, no âmbito das diferentes etapas e modalidades da educaçäo básica e da educação não formal.

Art. $2^{\circ}$ Para fins do disposto neste Decreto, considera-se:

I - alfabetização - ensino das habilidades de leitura e de escrita em um sistema alfabético, a fim de que o alfabetizando se torne capaz de ler e escrever palavras e textos com autonomia e compreensão;

II - analfabetismo absoluto - condiçāo daquele que nāo sabe ler nem escrever;

III - analfabetismo funcional - condição daquele que possui habilidades limitadas de leitura e de compreensão de texto;

IV - consciência fonêmica - conhecimento consciente das menores unidades fonológicas da fala e a habilidade de manipulá-las intencionalmente;

V - instrução fônica sistemática - ensino explícito e organizado das relações entre os grafemas da linguagem escrita e os fonemas da linguagem falada;

VI - fluência em leitura oral - capacidade de ler com precisão, velocidade e prosódia;

VII - literacia - conjunto de conhecimentos, habilidades e atitudes relacionadas com a leitura e a escrita e sua prática produtiva;

VIII - literacia familiar - conjunto de práticas e experiências relacionadas com a linguagem, a leitura e a escrita, as quais a criança vivencia com seus pais ou cuidadores;

IX - literacia emergente - conjunto de conhecimentos, habilidades e atitudes relacionadas com a leitura e a escrita desenvolvidos antes da alfabetização;

$X$ - numeracia - conjunto de conhecimentos, habilidades e atitudes relacionadas com a matemática; $e$

$\mathrm{XI}$ - educação não formal - designação dos processos de ensino e aprendizagem que ocorrem fora dos sistemas regulares de ensino.

\section{CAPITULO II}

\section{DOS PRINCIPIOS E OBJETIVOS}

Art. $3^{\circ}$ São princípios da Politica Nacional de Alfabetização:

I - integração e cooperação entre os entes federativos, respeitado o disposto no $\S 1^{\circ}$ do art. 211 da Constitução; Educação;

II - adesão voluntária dos entes federativos, por meio das redes públicas de ensino, a programas e ações do Ministério da

III - fundamentação de programas e açöes em evidências provenientes das ciências cognitivas;

IV - ênfase no ensino de seis componentes essenciais para a alfabetização:

a) consciência fonêmica;

b) instrução fônica sistemática;

c) fluência em leitura oral;

d) desenvolvimento de vocabulário;

e) compreensão de textos; $e$

f) produção de escrita: 
DECRETO N 9.765, DE 11 DE ABRIL DE 2019 - Diário Oficial da Ưnião - Imprensa Nacional

VI - integração entre as práticas pedagógicas de linguagem, literacia e numeracia;

VII - reconhecimento de que o desenvolvimento integral da criança pressupōe a inter-relação e a interdependência dos dominios físico, socioemocional, cognitivo, da linguagem, da literacia e da numeracia;

VIII - aprendizagem da leitura, da escrita e da matemática básica como instrumento de superação de vulnerabilidades sociais e condição para o exercicio pleno da cidadania;

IX - igualdade de oportunidades educacionais; $e$

$X$ - reconhecimento da família como um dos agentes do processo de alfabetização.

Art. $4^{\circ}$ São objetivos da Política Nacional de Alfabetização:

1 - elevar a qualidade do ensino e da aprendizagem no âmbito da alfabetização, da literacia e da numeracia, sobretudo nos primeiros anos do ensino fundamental, por meio de abordagens cientificamente fundamentadas;

II - contribuir para a consecução das Metas 5 e 9 do Plano Nacional de Educação de que trata o Anexo à Lei $n^{\circ} 13.005$, de 25 de junho de 2014;

III - assegurar o direito à alfabetização a fim de promover a cidadania e contribuir para o desenvolvimento social e econômico do País;

IV - impactar positivamente a aprendizagem no decorrer de toda a trajetória educacional, em suas diferentes etapas e niveis; e

V - promover o estudo, a divulgação e a aplicação do conhecimento científico sobre literacia, alfabetização e numeracia.

\section{CAPITULO III}

\section{DAS DIRETRIZES}

Art. $5^{\circ}$ Constituem diretrizes para a implementação da Politica Nacional de Alfabetização:

I - priorização da alfabetização no primeiro ano do ensino fundamental;

II - incentivo a práticas de ensino para o desenvolvimento da linguagem oral e da literacia emergente na educação infantil;

III - integraçăo de práticas motoras, musicalização, expressão dramática e outras formas artísticas ao desenvolvimento de habilidades fundamentais para a alfabetização;

IV - participação das familias no processo de alfabetização por meio de ações de cooperação e integração entre familias e comunidade escolar;

V - estímulo aos hábitos de leitura e escrita e à apreciação literária por meio de ações que os integrem à prática cotidiana das familias, escolas, bibliotecas e de outras instituiçōes educacionais, com vistas à formação de uma educação literária;

VI - respeito e suporte às particularidades da alfabetização nas diferentes modalidades especializadas de educação;

VII - incentivo à identificação precoce de dificuldades de aprendizagem de leitura, de escrita e de matemática, inclusive dos transtomos especificos de aprendizagem; e

VIII - valorização do professor da educação infantil e do professor alfabetizador.

\section{CAPITULO IV}

\section{DO PÚBLICO-ALVO}

Art. $6^{\circ} \mathrm{A}$ Política Nacional de Alfabetização tem por público-alvo:

l - crianças na primeira infância;

II - alunos dos anos iniciais do ensino fundamental;

III - alunos da educação básica regular que apresentam niveis insatisfatórios de alfabetização;

IV - alunos da educação de jovens e adultos;

$\checkmark$ - jovens e adultos sem matrícula no ensino formal; $e$

$\mathrm{VI}$ - alunos das modalidades especializadas de educação.

Parágrafo único. São beneficiários prioritários da Política Nacional de Alfabetização os grupos a que se referem os incisos le II do caput

Art. $7^{\circ}$ São agentes envolvidos na Política Nacional de Alfabetização:

I - professores da educação infantil;

II - professores alfabetizadores;

III - professores das diferentes modalidades especializadas de educação;

IV - demais professores da educação básica;

$V$-gestores escolares;

$\mathrm{VI}$ - dirigentes de redes públicas de ensino;

VII - instituições de ensino;

VIII - familias; e

IX - organizações da sociedade civil.

\section{CAPITULO V}




\section{DECRETO N 9.765, DE 11 DE ABRIL DE 2019 - Diário Oficial da União - Imprensa Nacional}

\section{DA IMPLEMENTAÇÄO}

Art. $8^{\circ}$ A Politica Nacional de Alfabetização será implementada por meio de programas, ações e instrumentos que incluam:

I - orientações curriculares e metas claras e objetivas para a educação infantil e para os anos iniciais do ensino fundamental;

II - desenvolvimento de materiais didático-pedagógicos cientificamente fundamentados para a literacia emergente, a alfabetização e a numeracia, e de ações de capacitação de professores para o uso desses materiais na educação infantil e nos anos iniciais do ensino fundamental;

III - recuperação e remediação para alunos que não tenham sido plenamente alfabetizados nos anos iniciais do ensino fundamental ou que apresentem dificuldades de aprendizagem de leitura, escrita e matemática básica;

IV - promoção de práticas de literacia familiar;

$\mathrm{V}$ - desenvolvimento de materiais didático-pedagógicos especificos para a alfabetização de jovens e adultos da educação formal e da educação não formal;

VI - produçäo e disseminação de sínteses de evidências científicas e de boas práticas de alfabetização, de literacia e de numeracia;

VII - estímulo para que as etapas de formação inicial e continuada de professores da educação infantil e de professores dos anos iniciais do ensino fundamental contemplem o ensino de ciências cognitivas e suas aplicaçöes nos processos de ensino e de aprendizagem;

VIII - ênfase no ensino de conhecimentos linguísticos e de metodologia de ensino de língua portuguesa e matemática nos curriculos de formação de professores da educação infantil e de professores dos anos iniciais do ensino fundamental;

IX - promoção de mecanismos de certificação de professores alfabetizadores e de livros e materiais didáticos de alfabetização e de matemática básica;

$X$ - difusão de recursos educacionais, preferencialmente com licenças autorais abertas, para ensino e aprendizagem de leitura, de escrita e de matemática básica:

$\mathrm{XI}$ - incentivo à produção e à edição de livros de literatura para diferentes niveis de literacia;

XII - incentivo à formação de gestores educacionais para dar suporte adequado aos professores da educaçăo infantil, aos professores do ensino fundamental $e$ aos alunos; $e$

XIII - incentivo à elaboração e à validaçăo de instrumentos de avaliação e diagnóstico.

\section{CAPÍTULO VI}

\section{DA AVALIAÇÃO E MONITORAMENTO}

Art. $9^{\circ}$ Constituem mecanismos de avaliação e monitoramento da Politica Nacional de Alfabetização:

I - avaliação de eficiência, eficácia e efetividade de programas e ações implementados;

II - incentivo à difusão tempestiva de análises devolutivas de avaliaçōes externas e ao seu uso nos processos de ensino e de aprendizagem;

III - desenvolvimento de indicadores para avaliar a eficácia escolar na alfabetizaçāo;

IV - desenvolvimento de indicadores de fluência em leitura oral e proficiência em escrita; $\theta$

$\mathrm{V}$ - incentivo ao desenvolvimento de pesquisas acadêmicas para avaliar programas e ações desta Política.

CAPITULO VII

\section{DISPOSIÇÕES FINAIS}

Art. 10. Compete ao Ministério da Educação a coordenação estratégica dos programas e das ações decorrentes desta Politica Nacional de Alfabetização.

Art. 11. A colaboração dos entes federativos na Política Nacional de Alfabetização se dará por meio de adesão voluntária, na forma a ser definida em instrumentos específicos dos respectivos programas e açōes do Ministério da Educação e de suas entidades vinculadas.

Art. 12. Para fins de implementação da Política Nacional de Alfabetização, a União poderá prestar assistência técnica e financeira aos entes federativos, que será definida em ato próprio de cada programa ou ação.

Art. 13. A assistência financeira da União, de que trata o art. 12, correrá por conta das dotações consignadas na Lei Orçamentária Anual ao Ministério da Educação e às suas entidades vinculadas, de acordo com a sua área de atuação, observados a disponibilidade e os limites estipulados na legislação orçamentária e financeira.

Art. 14. Este Decreto entra em vigor na data da sua publicaçāo.

Brasília, 11 de abril de 2019; $198^{\circ}$ da Independência e $131^{\circ}$ da República.

\section{JAIR MESSIAS BOLSONARO}

ABRAHAM BRAGANÇA DE VASCONCELLOS WEINTRAUB 